\title{
Consequences of Pre-Marital Sex among Female Undergraduate Students
}

\author{
Alade, T. T. Ph D, Owoeye, S. T, Bamidele, T. O \\ Department of Human Kinetics and Health Education, \\ Bamidele Olumilua University of Education, Science and Technology, Ikere-Ekiti (BOUESTI)
}

\begin{abstract}
The study investigated the consequences of pre-marital sex among female undergraduate students. In many societies, unmarried, single youths are sexually more active than what is commonly realized. There are several factors which encourage the pre-marital sexuality in cities; such as higher mobility and migration of younger people to towns and cities in search of jobs, massive urbanization resulting proliferation of slums, growing population, unemployment, influence of modern mass-media and information technology, better life-style, changing modes and erosion of traditional customs and social norms. The researchers used survey design of the descriptive type of research for the study. The research instrument used for this study was a self structure closed ended questionnaire designed by the researchers. The sample size of four hundred (400) respondents was used for the study. Purposive and simple random sampling techniques was used for the study. The face, content and construct validity of the instrument was ensured by given draft copies to experts for vetting. The reliability of the instrument was ensured by using the split half method of reliability, a coefficient of 0.78 was obtained. Pearson Product Moment Correlation (PPMC) was used to test the hypotheses at 0.05 level of significance. The finding of the study revealed that there was a significant relationship between vesico-vigina fistula (VVF) and pre-marital sex among undergraduate. It was also concluded that there was significant relationship between ectopic pregnancy and pre-marital sex among undergraduate students. The researchers recommended that management of institutions of learning should organise a seminar or orientation proramme to their female most importantly the newly admitted ones, as this will help to reduce the prevalence of pre-marital sex among them. Female undergraduate students should try to avoid multiple sexual partners in order to avoid ectopic pregnancy.
\end{abstract}

Keywords: Ectopic pregnancy, Pre-marital Sex, Vesico-vagina Fistula,

\section{INTRODUCTION}

$\mathrm{P}$ remarital sex is the involvement in sexual intercourse by persons who have not engaged in marital vow or culturally recognized as having been enrolled in marriage institution. Premarital sex is sexual activity practiced by people who are unmarried. Historically, premarital sex was considered a moral issue which was taboo in many cultures and considered a sin by a number of religions, but since about the 1960s, it has become more widely accepted, especially in Western countries. The terms premarital sex have been suggested, including non-marital sex (which overlaps with adultery), youthful sex, adolescent sex and young-adult sex. In some cultures, for example in many modern-day Western cultures, many people do not hold value in sexual abstinence before marriage (Sprecher, 2014).

Premarital sex is the involvement in sexual intercourse by persons who have not engaged in marital vow or culturally recognized as having been enrolled in marriage institution. Although marriage rites take different forms depending on cultural permissiveness, nevertheless the major thrust is the acceptance by the society. In most cases, premarital sex is not always a problem to individuals who are sexually matured since they may view it as a natural response to a natural stimulus. However, premarital sex is morally unacceptable in almost every human society that regards marriage as the legitimate requirement for sexual permissiveness, and especially among youths who are considered vulnerable to health related problems (Ajiboye, Aina, Oyebanji \& Awoniyi, 2014).

In many societies, unmarried, single youths are sexually more active than what is commonly realized. There are several factors which encourage the pre-marital sexuality in cities; such as higher mobility and migration of younger people to towns and cities in search of jobs, massive urbanization resulting proliferation of slums, growing population, unemployment, influence of modern mass-media and information technology, better life-style, changing modes and erosion of traditional customs and social norms (Olatunji, 2019).

University life is characterized, for many students, by more independence and opportunities for social mixing than before. The situation is aggravated by the overall poor socioeconomic, environment, harmful traditional practices, low contraceptive awareness (Adhikari, 2009). Sexual activities among students have been reported to be increasing worldwide; several studies in sub-Saharan Africa have also documented high and increasing premarital sexual activities among university students. Sexual activities among students have been reported to be increasing worldwide.

Different scholars identified inconsistent factors which were positively or negatively associated with premarital sexual practice among undergraduate students. Some of these factors includes age of students, residence, educational level, peer pressure, having pocket money, substance use, alcohol drink, watching pornography movie, living arrangement, discussion with parents about sexual issues, having peers who are 
experienced sex and fall in love and access religious and life skill education (Endazenaw \& Abebe, 2015). Premarital sex among students is a common phenomenon and is of particular importance because adolescent and young adults between 1524 years of age account for a vast proportion of newly acquired sexually transmitted diseases (Regassa, Chala \& Adeba, 2016).

It was observed by the researchers that the case of premarital sex in Nigeria is a serious problem because it affects an estimated one-quarter of sexually active teenagers in the country. The prevalence is high in various locations due to the poor knowledge of the diseases and the beliefs attached to it as a result of insufficient and inadequate information available to the teeming population from various quarters, especially adolescents who are sexually active. It was on this view the researchers intends to investigate the consequences of premarital sex among undergraduate students in University of Nigeria, Nsukka.

\section{Objectives of the study}

The study examined the consequences of pre-marital sex among undergraduate students of University of Nigeria, Nsukka. Specifically, the study examines the relationship between vesico-vigina fistula (VVF) and pre-marital sex. Also, the study investigated the relationship between ectopic pregnancy and pre-marital sex among undergraduate of University of Nigeria Nsukka, Ikere-Campus. Lastly, the study was designed to investigate the relationship between emotional disability pre-marital sex among undergraduate students' of University of Nigeria Nsukka, Ikere-Campus.

\section{Hypotheses}

The following hypotheses were tested for this study at 0.05 level of significance.

1. There is no significant relationship between vesicovigina fistula (VVF) and pre-marital sex among undergraduate of University of Nigeria Nsukka, IkereCampus.

2. There is no significant relationship between ectopic pregnancy and pre-marital sex among undergraduate students of university of Nigeria Nsukka, Ikerecampus.

3. There is no significant relationship between emotional disability and premarital sex among undergraduate students of university of Nigeria Nsukka, Ikerecampus.

\section{METHODOLOGY}

Survey design of the descriptive type of research was used for this study. This is considered as appropriate because the researcher will not manipulate any of the independent variables that is measured. The area of the study was University of Nigeria Nsukka, Ikere Campus, Ikere-Ekiti, Ekiti State.
The population of this study covered a total population of three thousand one hundred and forty students $(3,140)$, out of which degree one to degree four male students are one thousand four hundred and fifty-three students $(1,153)$, while the degree one to degree four female students are one thousand six hundred and eighty seven students $(1,687)$. (Source, Academic Planning, 2018). The sample size for this study was four hundred (400) female undergraduate students. Simple random sampling technique was used to select respondents. Selection of respondents was done according to the population of each departments/course of study. The instrument for data collection was a self-structured close ended questionnaire.

In order to validate the instrument for this study, drafts of the questionnaire prepared by the researchers were given to two (2) experts to vet in order to establish face, content and construct validity. Based on the suggestions that were made by these experts, the items were restructured where necessary and the corrected draft of the questionnaire was used for this study.

The reliability of the instrument was established using split half method of reliability. The researcher administer the instrument to forty (40) respondents from one of the department which aren't used for the final respondents; the instrument was divided into even and odd numbers. Therefore, two sets of data was generated. The data collected was analyze with the use of Pearson's Product Moment Conelation (PPMC) to determine the value of (r) at 0.05 level of significance. The coefficient $(r)$ of 0.78 was obtained. The questionnaire was administered to the respondents with the help of two (2) trained research assistants and completed questionnaire were retrieved from the respondents on the spot after filling.

The completed questionnaire was collected, coded and analysed. Inferential statistics of Pearson's Product Moment Correlation (PPMC) was used to test the hypotheses set for this study at 0.05 level of significance.

\section{RESULTS}

Hypothesis 1: There is no significant relationship between vesicovigina fistula (VVF) and pre-marital sex among undergraduate of University of Nigeria Nsukka, IkereCampus.

Table 1: Pearson Correlation Coefficient for relationship between pre-marital sex and vesico-vigina fistula (VVF)

\begin{tabular}{|c|c|c|c|}
\hline \multicolumn{2}{|c|}{} & $\begin{array}{c}\text { Consequence } \\
\text { of Pre-marital } \\
\text { sex }\end{array}$ & $\begin{array}{c}\text { Vesico-vigina } \\
\text { fistula (VVF) }\end{array}$ \\
\hline \multirow{3}{*}{$\begin{array}{c}\text { Consequence of } \\
\text { Pre-marital sex }\end{array}$} & Pearson Correlation & 1 & $.629^{* *}$ \\
\cline { 2 - 4 } & Sig. (2-taile//d) & & .000 \\
\cline { 2 - 4 } & $\mathrm{N}$ & 400 & 400 \\
\hline \multirow{3}{*}{$\begin{array}{l}\text { Vesico-vigina } \\
\text { fistula (VVF) }\end{array}$} & Pearson Correlation & $.629^{* *}$ & 1 \\
\cline { 2 - 4 } & Sig. (2-tailed) & .000 & \\
\cline { 2 - 4 } & $\mathrm{N}$ & 400 & 400 \\
\hline
\end{tabular}


$\mathrm{P}<0.05$

The result of analysis presented in table 1 revealed the relationship between pre-marital sex and vesico-vagina fistula among students in University of Nigeria, Nsukka, Ikere campus was high as r-coefficient was 0.629. The P-value (0.000) was less than 0.05 level of significance. This result led to the rejection of hypothesis one. This implies that there is relationship between vesico-vigina fistula (VVF) and premarital sex among undergraduate of University of Nigeria Nsukka, Ikere-Campus.

Hypothesis 2: There is no significant relationship between ectopic pregnancy and pre-marital sex among undergraduate students of university of Nigeria Nsukka, Ikere-campus.

Table 2: Pearson Correlation Coefficient for relationship between pre-marital sex and ectopic pregnancy

\begin{tabular}{|c|c|c|c|}
\hline \multicolumn{2}{|c|}{} & $\begin{array}{c}\text { Pre-marital } \\
\text { sex }\end{array}$ & $\begin{array}{c}\text { Ectopic } \\
\text { pregnancy }\end{array}$ \\
\hline \multirow{4}{*}{ Pre-marital sex } & Pearson Correlation & 1 & $.836^{* *}$ \\
\cline { 2 - 4 } & Sig. (2-tailed) & & .000 \\
\cline { 2 - 4 } & $\mathrm{N}$ & 400 & 400 \\
\hline \multirow{3}{*}{$\begin{array}{c}\text { Ectopic } \\
\text { pregnancy }\end{array}$} & Pearson Correlation & $.836^{* *}$ & 1 \\
\cline { 2 - 4 } & Sig. (2-tailed) & .000 & \\
\cline { 2 - 4 } & $\mathrm{N}$ & 400 & 400 \\
\hline
\end{tabular}

$\mathrm{P}<0.05$

The result of analysis presented in table 2 revealed the relationship between pre-marital sex and ectopic pregnancy among students in University of Nigeria, Nsukka, Ikere campus was high as r-coefficient was 0.836 . Also, the P-value (0.000) was less than 0.05 level of significance. This result led to the rejection of hypothesis two. This implies that there is relationship between ectopic pregnancy and pre-marital sex among undergraduate students of university of Nigeria Nsukka, Ikere-campus.

Hypothesis 6: There is no significant relationship between emotional disability and consequence of pre-marital sex among undergraduate students' of University of Nigeria Nsukka, Ikere-Campus.

Table 3: Pearson Correlation Coefficient for relationship between pre-marital sex and emotional disability

\begin{tabular}{|c|c|c|c|}
\hline \multicolumn{2}{|c|}{} & $\begin{array}{c}\text { Pre-marital } \\
\text { sex }\end{array}$ & $\begin{array}{c}\text { Emotional } \\
\text { disability }\end{array}$ \\
\hline \multirow{4}{*}{ Pre-marital sex } & Pearson Correlation & 1 & $.720^{* *}$ \\
\cline { 2 - 4 } & Sig. (2-tailed) & & .000 \\
\cline { 2 - 4 } & $\mathrm{N}$ & 400 & 400 \\
\hline \multirow{3}{*}{$\begin{array}{c}\text { Emotional } \\
\text { disability }\end{array}$} & Pearson Correlation & $.720^{* *}$ & 1 \\
\cline { 2 - 4 } & Sig. (2-tailed) & .000 & \\
\cline { 2 - 4 } & $\mathrm{N}$ & 400 & 400 \\
\hline
\end{tabular}

$\mathrm{P} \leq 0.05$
The result of analysis presented in table 3 revealed that the relationship between pre-marital sex and emotional disability among students in University of Nigeria, Nsukka, Ikere campus was high as r-coefficient was 0.720 . Also, the P-value (0.000) was less than 0.05 level of significance. This result led to the rejection of hypothesis three. This means that there is relationship between emotional disability and pre-marital sex among undergraduate students' of University of Nigeria Nsukka, Ikere-Campus.

\section{DISCUSSION}

The finding of hypothesis 1 revealed that there is a relationship between Vesico-vigina vistula and pre-marital sex. Other causes of VVF include urologic or gynecologic instrumentation, including percutaneous procedure, retroperitoneal, vascular or pelvic surgery, infectious and inflammatory diseases, foreign bodies (including neglected pessaries), sexual trauma, vaginal laser procedures and external violence leaking through the vagina (Stamatakos, Sargedi \& Konstantinos, 2014). Voluntary sexual intercourse in an adult woman with normal vagina is not a known cause of vesicovaginal fistula (VVF), though sexual abuse or sexual intercourse with young girls before reaching physical maturity can result in VVF. It was noted that majority of undergraduate students in Nigeria with University of Nigeria inclusive falls between the ages of 18-22 and their active involvement in premarital sex could trigger the excessive discharge of urine (VVF). Women with vesicovaginal fistulas often experience a disruption in their normal lives, including sexual relationships, because of urinary incontinence.

In a study conducted by Raji (2018) It was opined that patients diagnosed with VVF experience stress and emotional upheaval, fear of death, interruption of life plans, and change in social roles, lifestyle and medical bills, these are important issues to be faced all because of pre-marital sex. The finding from hypothesis 2 revealed that there is a relationship between ectopic pregnancy and pre-marital sex. The finding supported the finding of Assouni-Mindjah, Essiben, Foumane, Dohbit and Mboudou, (2018). Who carried out their study among Cameroonian women on the risk factors of ectopic pregnancy. In their finding they opined that female who had first sexual intercourse at less than 16years have the tendency of ectopic pregnancy occurrence and having more than five (5) sexual partners also increase the risk of ectopic pregnancy. There are other risk factors that have been associated with EP including prior EP, previous tubal surgery, documented tubal pathology, history of infertility, cigarette smoking, assisted reproduction technologies (ARTs), multiple lifetime sexual partners, older maternal age, and in utero diethylstilbestrol (DES) exposure (Bray-Madoue, Saleh, Serge, Tchari \& Kolombo, 2016).

The finding from fro hypothesis 3 revealed that there is a relationship between pre-marital sex and emotional disability. The finding was in line with the view of Hurissa, Tebeje and Megersa (2014) who opined that adolescent who engage in pre-marital sex may end up with unwanted pregnancies, 
abortions, teenage deliveries, emotional disability and various complications of these including death.

\section{CONCLUSION}

Based on the result from the study, the researchers concluded that there was relationship between vesico-vigina fistula (VVF) and pre-marital sex, there was relationship between ectopic pregnancy and pre-marital sex. The researchers recommended that management of institutions of learning should organise a seminar or orientation proramme to their female most importantly the newly admitted ones, as this will help to reduce the prevalence of pre-marital sex among them. Female undergraduate students should try to avoid multiple sexual partners in order to avoid ectopic pregnancy.

\section{REFERENCES}

[1] Adhikari, R. (2009). Premarital sexual behaviour among college students of Kathmandu, Nepal: BMC public Health 9, 241.

[2] Ajiboye, S. K., Aina, J. S., Oyebanji, T. O. \& Awoniyi, S. A. (2014). Possible causes of premarital sex among youths as perceived by lecturers of university of Ilorin, Nigeria.European Journal of Educational Sciences. (1), 4.

[3] Assouni-Mindjah, Y. A., Essiben, F., Foumane, P., Dohbit, J. S. \& Mboudou, E. T. (2018). Risk factors for ectopic pregnancy in a population of Cameroonian women: A case-control study.
PLoSONE

13(12), e0207699.https://doi.org/10.1371/journal.pone.0207699.

[4] Bray-Madoue, G., Saleh, A., Serge, R. I,, Tchari A. \& Kolombo, D. (2016). Grossesse extra-utérine: Aspects épidémiologiques et Pronostic maternel à l'Hôpital de district de N'djamena sud (Tchad). Kisangani Méd. 6(1),111-116.

[5] Olatunji, M. P. (2019). Consequences of pre-marital sex among undergraduate students of university of Nigeria, Nsukka, Ikere campus. A project (unpublished) submitted to the department of Human Kinetics and Health Education, University of Nigeria, Nsukka.

[6] Sprecher, S. (2014). Evidence of change in men's versus women's emotional reactions to first sexual intercourse: a 23 -year study in a human sexuality course at a midwestern university. Journal of Sexual Res, 51(4), 466-72.

[7] Stamatakos, M., Sargedi, C. \& Konstantinos, K. (2014). Vesicovaginal Fistula: Diagnosis and Management. Indian journal of surgery, 76(2), 131-136.

[8] Hurissa, B. F, Tebeje, B, Megersa, H. (2014). Prevalence of Premarital Sexual Practices and Associated Factors among Jimma Teacher Training College Students in Jimma Town, South West Shoa Zone, Oromiya Region, Ethiopia. Journal of Women's Health Care 4: 221. doi:10.4172/2167-0420.1000221

[9] Raji, M.O., (2018). Knowledge, effect of vesico vaginal fistula (VVF) and satisfaction with VVF repair related services in a fistula repair facility in North Western Nigeria. International Journal of Contemporary Medical Research 5 (9), 11-I6. 